University of Nebraska - Lincoln

DigitalCommons@University of Nebraska - Lincoln

P. F. (Paul Frazer) Williams Publications

Electrical \& Computer Engineering, Department

February 1996

\title{
Schlieren Photography of Current Filaments in Surface-Related Breakdown of Silicon
}

\author{
B. J. Hankla \\ University of Nebraska - Lincoln \\ P. F. Williams \\ University of Nebraska - Lincoln, pfw@moi.unl.edu
}

Follow this and additional works at: https://digitalcommons.unl.edu/elecengwilliams

Part of the Electrical and Computer Engineering Commons

Hankla, B. J. and Williams, P. F., "Schlieren Photography of Current Filaments in Surface-Related Breakdown of Silicon" (1996). P. F. (Paul Frazer) Williams Publications. 16.

https://digitalcommons.unl.edu/elecengwilliams/16

This Article is brought to you for free and open access by the Electrical \& Computer Engineering, Department of at DigitalCommons@University of Nebraska - Lincoln. It has been accepted for inclusion in P. F. (Paul Frazer) Williams Publications by an authorized administrator of DigitalCommons@University of Nebraska - Lincoln. 


\title{
Schlieren Photography of Current Filaments in Surface-Related Breakdown of Silicon
}

\author{
B. J. Hankla and P. F. Williams
}

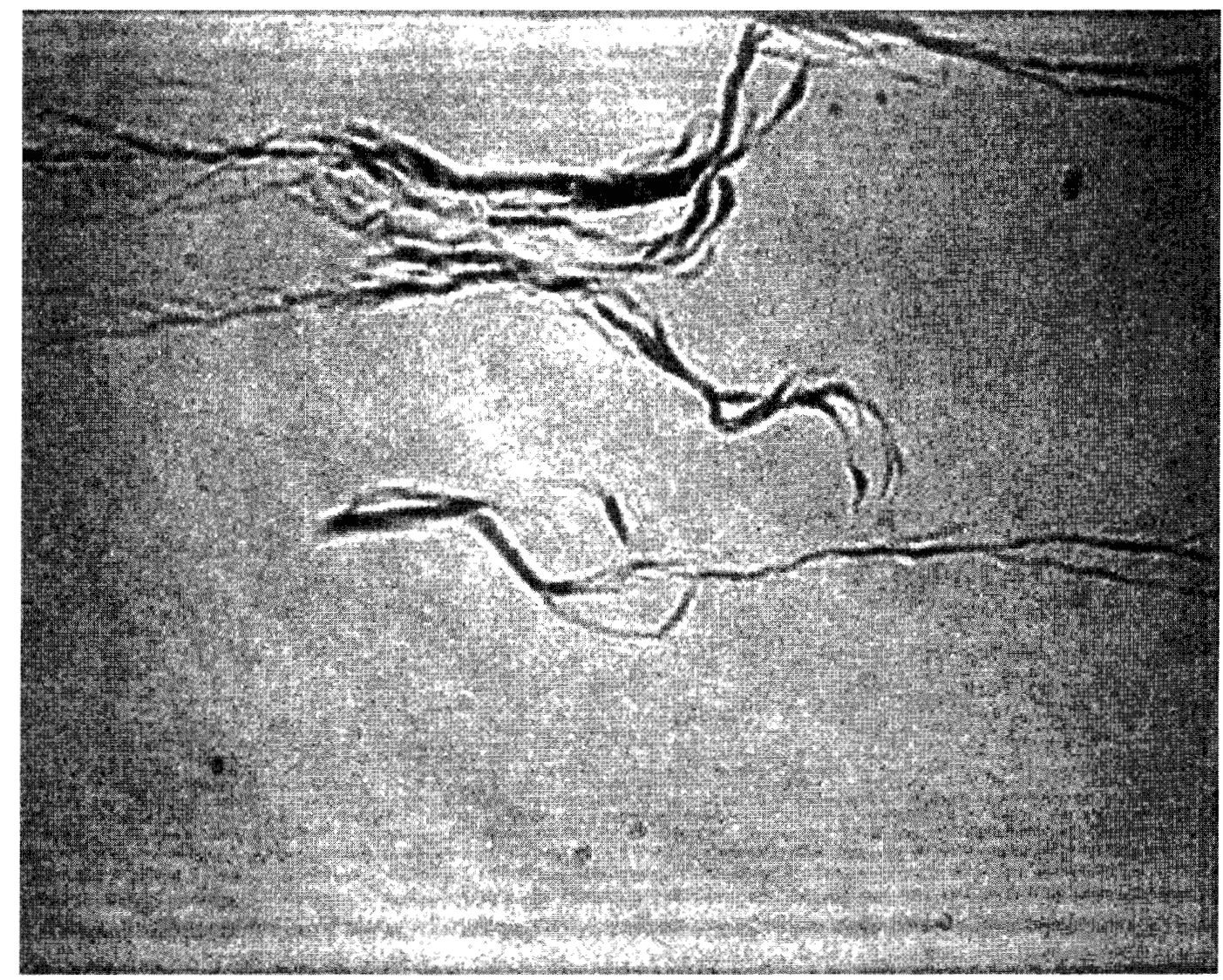

Fig. 1. Schlieren photograph showing filament formation in a $\mathrm{p}^{+}-\mathrm{p}^{-}-\mathrm{n}^{-}$device. The photo was taken about $70 \mathrm{~ns}$ after the onset of breakdown.

\begin{abstract}
We have used a modified Schlieren technique to photograph current filaments formed inside silicon during the very early stages of surface-related breakdown. We believe that the features we see are due to heating in the filamentary channel. The very rapid formation of these channels suggests that they result from streamer-like phenomena in the bulk silicon.
\end{abstract}

\footnotetext{
A surface-related breakdown process often sets the voltage threshold for semiconductor devices, but the physical basis for the process is not understood. The breakdown occurs in fields well below the dielectric strength of the semiconductor, and is frequently termed "surface flashover" since it is frequently accompanied by weak visible emission. We

Manuscript received July 17, 1995

The authors are with the Department of Electrical Engineering, University of Nebraska-Lincoln, Lincoln, NE 68588-0511 USA.

Publisher Item Identifier S 0093-3813(96)02240-0.
}

have been using a Schlieren-like technique [1] to obtain time-resolved images of the events occurring very early in the breakdown process. Filamentary features appear in these images within typically $10-15 \mathrm{~ns}$ of the start of the breakdown event, and rapidly evolve into complex structures similar to those seen in the breakdown of atmospheric pressure gases.

The sample for these studies is a rectangular prism of highpurity silicon with dimensions $1 \times 0.8 \times 0.2 \mathrm{~cm}$. The faces are prepared using a standard chemomechanical polishing process to make low-damage optical-quality surfaces. Phosphorous or boron are diffused into the $0.8 \times 0.2$ faces to form $\mathrm{n}^{+}$or $\mathrm{p}^{+}$ regions, and aluminum is evaporated over these surfaces and annealed to provide convenient contact. We have used both $\mathrm{n}^{-}$and $\mathrm{p}^{-}$bulk material with carrier density in the $10^{11}-10^{12}$ $\mathrm{cm}^{-3}$ range to make devices. We have investigated all six possible device configurations, but show results only for a $\mathrm{p}^{+}-\mathrm{p}^{-}-\mathrm{n}^{+}$device. In low-voltage $I-V$ measurements (up to 
$800 \mathrm{~V}$ ), the device displayed a rectifying characteristic. For voltages below about $100 \mathrm{~V}$ in the forward direction, the current was about what is expected based on the measured bulk resistivity, but it increased superlinearly with voltage above this point. This superlinear characteristic is not well understood, but we believe it is due to double injection.

To obtain the images, the sample is mounted between copper electrodes in a vacuum cell, and the cell is evacuated to less than $1 \times 10^{-6}$ torr. One electrode is connected to a pulse generator producing pulses with about 15 -ns risetime, and typically $30-\mathrm{kV}$ magnitude. The other electrode was connected through a $50-\Omega$ resistor to ground. The sample orientation is such that the voltage is applied across the $1-\mathrm{cm}$ dimension of the sample.

To obtain the images, a much-attenuated and spatially filtered 1064-nm beam from a Quanta Ray DCR3 Nd:YAG laser is passed through the $0.2-\mathrm{cm}$ dimension of the sample. The beam is then passed through a second spatial filter consisting of an imaging lens and a $0.2-\mathrm{cm}$ diameter iris placed at its focus. The lens is adjusted to provide an image of the sample on the active surface of a sensitive charge-coupled device (CCD) camera (PAR OMA 4). Optical emission from the sample is discriminated against using a 3-mm thick Schott RG 850 long-wavelength-pass filter. Rays which pass through the sample undeflected pass through the iris and are imaged onto the camera face. Rays deflected due to an inhomogeneous index of refraction in the sample may not pass through the iris, and the corresponding regions will appear darkened in the image. The time resolution of the system is determined by the temporal width of the Nd:YAG laser, and is about $10 \mathrm{~ns}$ in this case.

The sensitivity of the technique to index variation is determined by the iris diameter. One cannot freely reduce this diameter, however, because the focal plane of the imaging lens contains the Fourier transform of the object. Reducing the iris diameter reduces, therefore, the spatial resolution of the imaging system. For our setup, our best sensitivity is about $\Delta n_{\min } \approx 0.01$.

Fig. 1 shows a typical photograph obtained from a $\mathrm{p}^{+}-\mathrm{p}^{-}-\mathrm{n}^{+}$device about $70 \mathrm{~ns}$ after the onset of breakdown. The structures seen are due to variations in the index of refraction in the silicon, caused, we believe, by heating in the current filaments. Using the data of Jellison and Modine [2], we estimate that a temperature variation of about $40^{\circ} \mathrm{C}$ would be easily visible. Carrier density can also modify the index of refraction. Using a simple Drude model, we estimate that a carrier density of $10^{18} \mathrm{~cm}^{-3}$ would produce an index variation of only about $10^{-4}$. It is on this basis that we conclude that the structures we see are produced by localized heating.

Although this particular photograph was taken relatively late in the process, the structures first appear about $20 \mathrm{~ns}$ after the voltage is applied. The appearance of filamentary structures so early in the breakdown process is surprising, and it raises the question of what physical mechanism is responsible. We believe the most likely explanation to be the formation and propagation of streamer-like phenomena. The existence of streamer-like domains in semiconductors was first proposed by D'yakonov and Kachorovskii [3], and several workers have suggested that they might be responsible for the "lock-on" effect observed in GaAs [4], [5].

\section{REFERENCES}

[1] L. A. Vasilev, Schlieren Methods. New York: Keter, 1986.

[2] G. E. Jellison, Jr. and F. A. Modine, "Optical functions of silicon at elevated temperatures," J. Appl. Phys., vol. 76, pp. 3758-3761, 1994.

[3] M. I. D'yakonov and V. Y. Kachorovskii, "Streamer discharge in a homogeneous field" Sov. Phys. JETP vol. 68, pp. 1070-1074, 1989.

[4] J. C. Adams, C. C. Capps, R. A. Falk, and S. G. Ferrier, "Below bandgap electroabsorption in bulk semi-insulating GaAs," Appl. Phys. Lett., vol. 63, pp. 633-635, 1993.

[5] G. M. Loubriel, F. J. Zutavern, H. P. Hjalmarson, R. R. Gallegos, W. D. Helgeson, and M. W. O'Malley, "Measurement of the velocity of current filaments in optically triggered, high gain GaAs switches," Appl. Phys. Lett., vol. 64, pp. 3323-3325, 1994. 